Al-Ishlah: Jurnal Pendidikan - ISSN: 2087-949o (p); 2597-940X (e)

Vol. 11, No. 1 (2019)

\title{
PENGARUH JUMLAH DESA YANG MEMILIKI FASILITAS SEKOLAH TERHADAP PENDUDUK BUTA HURUF DI PROVINSI KEPULAUAN BANGKA BELITUNG
}

\author{
Elly Oktalina \\ SMA Negeri 2 Pangkal Pinang \\ Email: ellyoktalina10@gmail.com
}

\begin{abstract}
Abstrak
This study aims to find out how the development of the number of villages that have school facilities in the Province of Bangka Belitung Islands, and analyze the development of the percentage of illiterate population in the Bangka Belitung Islands Province, compare it with the percentage of national illiterate population and analyze the influence of the number of villages that have school facilities on blind residents letters in the Province of Bangka Belitung Islands. This research is a quantitative study, using statistical analysis with linear regression data analysis techniques and validation tests of ANOVA analysis. This research uses data from the pages of the Bangka Belitung Islands Provincial Statistics Agency from 2011 to 2018. Based on the research that has been done, it can be concluded that there has been an increase in the number of villages that have school facilities in the Bangka Belitung Islands Province of $32 \%$ to $36 \%$ in contrast The percentage of illiterate people in the Bangka Belitung Islands Province has decreased from $17.41 \%$ to $2.91 \%$. This $2.91 \%$ figure is lower than the national percentage of $4.88 \%$. Based on regression analysis with a regression coefficient of 0.940 and the regression equation $Y=-0.860 X+128.2$ and ANOVA analysis with a p-value of 0.0038 and significance 0.0049 can be concluded a variable increase in the number of villages that have school facilities resulting in a decrease variable percentage of illiterate population in Bangka Belitung island province.
\end{abstract}

Penelitian ini bertujuan mengetahui perkembangan jumlah desa yang memiliki fasilitas sekolah dan menganalisis perkembangan persentase penduduk buta huruf di Provinsi Kepulauan Bangka Belitung, membandingkannya dengan persentase penduduk buta huruf nasional, serta menganalisis pengaruh jumlah desa yang memiliki fasilitas sekolah terhadap penduduk buta huruf di Provinsi Kepulauan Bangka Belitung. Penelitian ini merupakan penelitian kuantitatif menggunakan analisis statistic dengan teknik analisis data regresi linear dan uji validasi analisis anova. Penelitian ini menggunaan data dari laman Badan Pusat Statistik Provinsi Kepulauan Bangka Belitung mulai tahun 2011 sampai 2018. Berdasarkan penelitian yang telah dilakukan dapat diambil kesimpulan bahwa telah terjadi peningkatan jumlah rata-rata desa yang memiliki fasilitas sekolah di Provinsi Kepulauan Bangka Belitung, yaitu dari 32\% menjadi 36\%. Sebaliknya persentase penduduk buta huruf di Provinsi Kepulauan Bangka Belitung telah terjadi penurunan dari 17,41\% menjadi 2,9\%. Angka 2,91\% ini lebih rendah 
Al-Ishlah: Jurnal Pendidikan - ISSN: 2087-949o (p); 2597-940X (e)

Vol. 11, No. 1 (2019)

jika dibandingkan persentase nasional sebesar 4,88\%. Berdasarkan analisis regresi dengan koefisien regresi sebesar 0,940 dan persamaan regresi $Y=-$ $0,860 \mathrm{X}+128,2$ dan analisis anova dengan nilai p-value 0,0038 dan significance 0,0049 dapat diambil kesimpulan variable peningkatan jumlah desa yang memiliki fasilitas sekolah mengakibatkan turunnya variable persentase penduduk buta huruf di Propinsi Kepulauan Bangka Belitung.

Kata Kunci: Desa, Fasilitas Sekolah, Penduduk Buta Aksara

\section{PENDAHULUAN}

Pendidikan merupakan usaha sadar dan terencana untuk mewujudkan suasana belajar dan proses pembelajaran agar peserta didik secara aktif mengembangkan potensi dirinya untuk memiliki kekuatan spiritual keagamaaan, pengendalian diri, kepribadian, kecerdasan, akhlak mulia, serta keterampilan yang diperlukan dirinya, masyarakat, bangsa, dan negara. Belajar tidak hanya sekadar menambah ilmu pengetahuan, tetapi adanya perubahan tingkah laku pada individu-individu yang belajar. Perubahan itu tidak hanya berkaitan dengan penambahan ilmu pengetahuan, tetapi juga berbentuk kecakapan, watak, minat, dan penyesuaian diri. Jadi, dapat dikatakan bahwa belajar itu sebagai rangkaian kegiatan jiwa raga menuju perkembangan pribadi manusia seutuhnya. Belajar akan membentuk manusia hebat dan kuat dan berakhlak mulia yang mampu berkembang dengan pesat serta mampu menyesuaikan diri dengan kemajuan zaman.

Sekolah merupakan lembaga formal yang diharapkan dapat menjadikan manusia lebih baik. Sebagai lembaga pendidikan, sekolah sangat erat kaitannya dengan belajar. Belajar adalah suatu upaya untuk mencapai tujuan pendidikan. Faktor yang sangat mendukung tercapainya tujuan pendidikan adalah fasilitas pendidikan seperti dikemukakan para ahli berikut. Pertama, fasilitas sekolah serta lingkungan sosial yang parsial menunjukkan signifikan terhadap hasil belajarsiswa (Nik Amah, Angga Nugroho, 2015). Kedua, salah satu faktor yang dapat menunjang hasil belajar siswa adalah faktor instrument sepertihalnya fasilitas sekolah (Mulyasa, 2011).

Fasilitas sekolah adalah peralatan atau perlengkapan yang secara langsung dipergunakan untuk menunjang proses pendidikan, khususnya proses belajar mengajar, seperti Gedung, ruang, meja, kursi, serta alat-alat media (Mulyasa, 2011). Fasilitas merupakan sarana dan prasarana yang harus tersedia untuk melancarkan kegiatan pendidikan di sekolah (Sopiatin, 2010). Fasilitas atau sarana dan prasarana merupakan salah satu sumber daya pendidikan yang perlu dan sangat penting dikelola dengan baik serta merupakan bagian yang tidak dapat 
Al-Ishlah: Jurnal Pendidikan - ISSN: 2087-949o (p); 2597-940X (e)

Vol. 11, No. 1 (2019)

dipisahkan dari manajemen pendidikan, seperti gedung, tanah, perlengkapan administrasi, sampai pada sarana yang digunakan langsung dalam proses belajar mengajar di kelas (Rika Megasari, 2014).

Terpenuhinya sarana dan prasarana pembelajaran disekolahakan mendukung proses pembelajaran. Hal ini tentu saja dapat menyebabkan kegiatan belajar mengajar berlangsung dengan efektif dan efisien sehingga sangat menunjang tercapainya pendidikan berkualitas yang merupakan syarat bagi upaya peningkatan mutu pendidikan (Nurcahyo Aridhiyant, 2015). Salah satu tolak ukur mutu pendidikan dalam masyarakat adalah persentase penduduk buta huruf. Keberhasilan pendidikan suatu negara sangat mudah dilihat dengan persentase penduduk buta huruf. Angka buta huruf di Indonesia mengalami penurunan signifikan setiap tahun. Pada 2014, angka buta huruf di Indonesia sebesar 4,88\% atau sekitar 6.007.486 orang. Namun, pemerintah Indonesia masih memiliki pekerjaan rumah untuk menuntaskan 6.007.486 penduduk buta aksara (Maharani dan Wiwiek Setya Winahju, 2014).

Novi Widiastuti (2013) dalam skripsinya yang berjudul "Penerapan Metode Pembelajaran Trans literasi alam Meningkatkan Hasil Belajar Keaksaraan" menuliskan pendidikan merupakan salah satu strategi dalam mewujudkan pembangunan nasional. Pendidikan yang paling mendasar adalah pendidikan keaksaraan karena melek aksara merupakan modalawal dalam memperoleh informasi di dunia ini. Agama Islam pun mengajarkan iqra yang artinya adalah 'baca'. Melek aksara bukan hanya sekadar mampu membaca, menulis, dan berhitung, sebagaimana disebutkan dalam sebuah artikel yang berjudul "A new tool for assessing and monitoring literacy" $(S)$, yaitu: measuring literacy is not just a matter of saying who can read and who cannot. Many different levels of literacy skills are needed, from writing one's name to understanding instructions on a medicine bottle to learning from books. With literacy at the top of the development agenda, good data are needed to help design and target appropriate actions, whether at the national or local level.

Novi Widiastuti (2012) juga mengemukakan bahwa menurut data Kementerian Pendidikan Nasional, angka buta huruf di Indonesia mencapai 8,5 juta jiwa, dengan 5,1 juta diantaranya adalah perempuan. Jumlah ini menurun dari tahun 2004 lalu, yaitu dengan angka 15 juta penduduk. Keberhasilan tersebut membuat Indonesia mendapatkan penghargaan UNESCO's Literacy Prizes for 2012 bersama Bhutan, Rwanda, dan Kolumbia. Namun walaupun demikian, angka tersebut masuk dalam kategori angka buta aksara terbesar di dunia

Buta aksara secara umum dapat dikelompokkan menjadi: 1) buta huruf murni, kelompok yangdapat dikategorikan pada masyarakat yang tidak beruntung, karena sama sekali tidak pernah menerima layanan pendidikan sekolah; 2) 
Al-Ishlah: Jurnal Pendidikan - ISSN: 2087-949o (p); 2597-940X (e)

Vol. 11, No. 1 (2019)

penduduk yang pernah menikmati pendidikan sekolah, tetapi drop out akibat berbagai alasan, seperti lemah kemampuan ekonominya atau tidak puas dengan layanan pendidikan; 3) kelompok masyarakat yang sebenarnya telah bisa membaca, tetapi kemampuan menulisnya masih lemah yang di sebabkan minimnya latihan dan/atau kemampuan membaca dan menulis yang telah dimilikinya itu tidak biasa dipergunakan kembali; 4) kelompok masyarakat yang lebih mengenal huruf dan juga bilangan, tetapi tidak bisa merangkainya. Hal ini disebabkan oleh minimnya latihan dan tidak ada rangsangan untuk mau dan mampu membelajarkan diri; 5) penduduk yang telah mengenal huruf, tetapi apabila dihadapkan pada huruf-huruf ganda, seperti /ng/, /ny/, dan /kh/ mengalami kesulitan untuk membaca

Perbedaan fasilitas pendidikan di kota dan di desa sangat terlihat. Fasilitas sekolah di perkotaan dan di pedesaan berbanding terbalik. Sekolah yang terdapat di perkotaan, dengan bangunan yang nyaman dan aman untuk ditempati. Fasilitas yang sangat memadai, seperti ruangan komputer, sarana olahraga, ruangan puskesmas dan kantin maka akan membuat suasana belajar akan sangat nyaman bagi siswa- siswa yang bersekolah di perkotaan. Jika dibandingkan dari dengan sarana dan prasana pendidikan di pedesaan dan di perkotaan tentu akan terlihat sekali kesenjangan pendidikan. (Benediktus Vito, Hetty Krisnani, \& Risna Resnawaty, 2015).

Provinsi Kepulauan Bangka Belitung memiliki 445 pulau yang didalam yang tersebar 391 desa (Ditjen Kependudukan dan Catatan Sipil, Kemendagri). Dengan kondisi geografis tersebut, sangat memungkinkan terdapat kesulitan dalam pemenuhan fasilitas sekolah dan kesulitan untuk memberantas buta huruf sehingga terjadilah kesenjangan pada pemenuhan fasilitas sekolah. Hal ini berpotensi memunculkan masalah sebagai berikut. 1) Bagaimana perkembangan jumlah desa yang memiliki fasilitas sekolah di Provinsi Kepulauan Bangka Belitung? 2) Bagaimana perkembangan persentase penduduk buta huruf di Provinsi Kepulauan Bangka Belitung? 3) Bagaimana hubungan antara jumlah desa yang memiliki fasilitas sekolah terhadap persentase jumlah penduduk buta huruf di Provinsi Kepulauan Bangka Belitung?

Manfaat dari penelitian ini adalah untuk memberikan masukan pada pemerintah agar dapat digunakan untuk mendapatkan informasi kondisi jumlah desa yang memiliki fasiltas sekolah dan perkembangan penduduk buta huruf yang berpengaruh terhadap peningkatan fasilitas sekolah di desa, serta upaya-upaya untuk memberantas buta huruf. 
Al-Ishlah: Jurnal Pendidikan - ISSN: 2087-949o (p); 2597-940X (e)

Vol. 11, No. 1 (2019)

\section{METODE PENELITIAN}

Jenis penelitian yang digunakan dalam penelitian ini adalah kuantitatif analitik dengan metode penelitian korelasional. Teknik perhitungan statitik digunakan untuk menentukan persamaaan regresi linear. Analisis data pada penelitian ini menggunakan data sekunder yang diambil dari BPS dengan cara mengunduh data menggunakan situs BPS. Go. id pada 14 Maret 2019. Data yang digunakan adalah data jumlah desa yang memiliki fasilitas sekolah, mulai dari jenjang SD sampai perguruan tinggi di Provinsi Kepulaan Bangka Belitung dan data persentase penduduk buta huruf pada kelompok usia dibawah 14 tahun, usia antara 15 tahun sampai 44 tahun, dan usia lebih dari 45 tahun di Provinsi Kepulauan Bangka Belitung.

Tahapan penelitian dimulai dari menganalisis jumlah desa yang memiliki fasiltas sekolah, lalu menganalisis persentase jumlah penduduk buta huruf, serta membandingkannya dengan persentase penduduk buta huruf nasional. Setelah itu dilakukan penganalisisan hubungan antara jumlah desa yang memiliki fasilitas sekolah dengan persentase penduduk buta huruf menggunakan regresi linear:

$$
\begin{aligned}
& \mathrm{Y}=\mathrm{a}+\mathrm{bX} \\
& \mathrm{Y}=\text { variabel tak bebas } \\
& \mathrm{X}=\text { variabel bebas } \\
& \mathrm{A}=\text { konttanta } \\
& \mathrm{B}=\text { parameter koefisien regresi variabel }
\end{aligned}
$$

Persentase penduduk buta huruf di Provinsi Kepulauan Bangka Belitung sebagai variabel Y dan jumlah sekolah yang memiliki fasilitas sekolah di Provinsi Kepulauan Bangka Belitung sebagai variabel X. Dari persaman regresi linear dapat ditentukan korelasi variabel $\mathrm{X}$ dan variabel $\mathrm{Y}$. Selanjutnya, untuk mengetahui validitas hubungan variabel $\mathrm{X}$ danvariabel $\mathrm{Y}$ diatas digunakan analisis anova dalam menetukan $\mathrm{p}$-value dan signifikan hasil penelitian.

\section{HASIL PENELITIAN DAN PEMBAHASAN}

Jumlah desa yang memiliki fasilitas sekolah di Provinsi Kepulauan Bangka Belitung untuk jenjang sekolah dasar, sekolah menengah pertama, sekolah menengah atas, sekolah kejuruan,dan perguruan tinggi pada 2011, 2014, dan 2018 diperoleh dengan mengunduh data dari Badan Pusat Statistik. Akan tetapi, karena data yang didapat hanya 3 tahun saja, perlu dilakukan penambahan data untuk melengkapi data statistik itu. Untuk itu, ditambahkan angka perkiraan pada 2013 yaitu dengan menambahkan jumlah desa pada 2011 dengan jumlah desa pada 2014 lalu dibagi 2, begitu juga dengan angka perkiraan jumlah desa pada tahun 2016 yaitu dengan menambahkan jumlah desa pada2014 ditambah jumlah 
Al-Ishlah: Jurnal Pendidikan - ISSN: 2087-949o (p); 2597-940X (e)

Vol. 11, No. 1 (2019)

desa pada 2018 dibagi 2. Perbandingan desa yang memiliki fasilitas sekolah dari tahun 2011 sampai 2018 di Provinsi Kepulauan Bangka Belitung dapat dilihat pada gambar 1 di bawah ini.

Jumlah Desa yang

Memiki Fasilitas

Sekolah

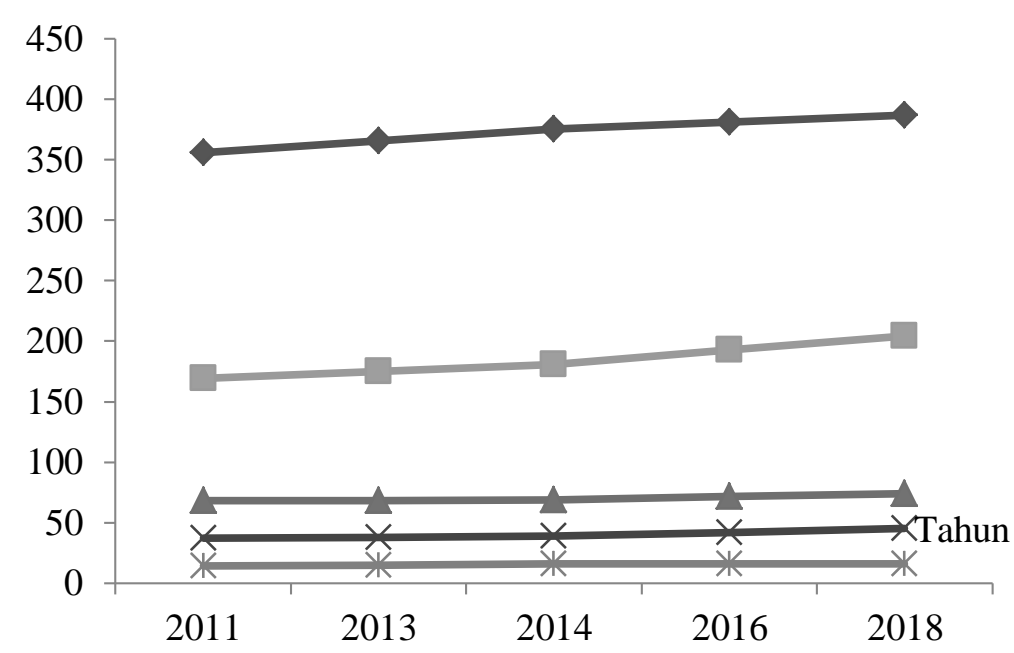

\section{Gambar 1. Grafik perbandingan desa yang memiliki fasilitas sekolah dari tahun 2011 sampai 2018 di Povinsi Kepulauan Bangka Belitung}

Berdasarkan grafik di atas dapat dilihat perkembangan jumlah desa yang memiliki fasilitas sekolah dari tahun 2011 sampai 2018. Perkembangan paling tinggi terjadi pada jenjang SD, yaitu lebih dari 356 SD pada 399 jumlah desa yang tersebar di Provinsi Kepulauan Bangka Belitung memiliki fasilitas sekolah dengan kecenderungan tren grafik meningkat. Hampir semua desa memiliki fasiltas sekolah tren grafik naik dari 89\% sampai 97\% ni berarti pada 2018 hanya 3\% desa yang tidak memiliki fasilitas sekolah. Perkembangan jumlah desa yang memiliki fasitas SMP menunjukan lebih dari 169 desa yang memiliki fasilitas SMP dengan tren grafik naik dari $42 \%$ sampai 51\%. Jadi pada 2018 rata-rata untuk 2 desa memiliki fasilitas SMP. Perkembangan jumlah desa yang memiliki fasilitas SMA menunjukan lebih dari 68 desa yang memiki fasilitas SMA dengan tren grafik naik dari $17 \%$ sampai $18 \%$. Perkembangan desa yang memiliki fasilitas SMK, menunjukkan lebih dari 73 desa yang memiliki fasilitas SMK dengan tren grafik naik dari 9,4\% sampai $11,2 \%$. Terakhir, perkembangan desa yang memiliki fasilitas perguruan tinggi menunjukkan angka lebih dari 4 desa dengan tren grafik naik sedikit dari 3,8\% ke 4,4\%. Apabila jumlah desa yang memiliki fasilitas sekolah mulai dari jenjang SD, SMP, SMA, SMK, serta 
Al-Ishlah: Jurnal Pendidikan - ISSN: 2087-949o (p); 2597-940X (e)

Vol. 11, No. 1 (2019)

perguruan tinggi ini dijumlahkan lalu dibagi 5, didapatlah jumlah rata-rata fasilitas sekolah yang dimiliki desa-desa dari tahun 2011 sampai 2018 terlihat adanya tren peningkatan jumlahdesa yang memiliki fasilitas sekolah, seperti yang terlihat pada grafik gambar 2.

Jumlah Desa yang

Memiliki Fasilitas

Sekolah Rata-rata

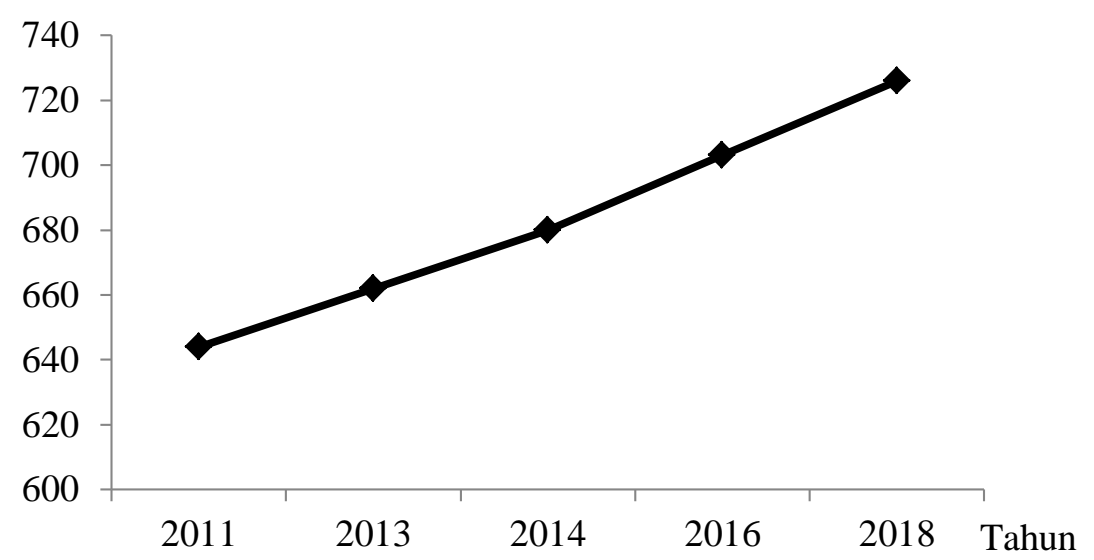

\section{Gambar 2. Grafik perkembangan desa yang memiliki fasilitas sekolah dari tahun 2011 sampai 2018}

Berdasarkan grafik diatas, perkembangan rata-rata desa yang memiliki fasilitas sekolah dari tahun 2011 lebih dari 128 desa dari 399 desa yang memiliki fasilitas sekolah menunjukkan tren grafik naik dengan kenaikan dari $32 \%$ sampai $36 \%$. Untuk mengetahui persentase penduduk buta huruf di Provinsi Kepulauan Bangka Belitung juga diambil data BPS, seperti terlihat pada grafik gambar 3 dibawah ini. Pada grafik tersebut dapat dilihat persentase penduduk buta huruf didominasi penduduk usia 45 tahun keatas dengan tren garafik turun dari 10,43\% menjadi $5,53 \%$. Tren grafik untuk kelompok usia dibawah 14 tahun menurun dari $4,54 \%$ menjadi $2,21 \%$, dan, yang paling sedikit, penduduk buta huruf pada kelompok usia 15 sampai 44 tahun dengan tren grafik menurun dari 2,13\% menjadi $0,7 \%$. Secara umum, dapat dilihat tren grafik cenderung turun yang berarti persentase penduduk buta huruf mengalami penunurunan, seperti yang terlihat pada grafik gambar 3 . 
Al-Ishlah: Jurnal Pendidikan - ISSN: 2087-949o (p); 2597-940X (e)

Vol. 11, No. 1 (2019)

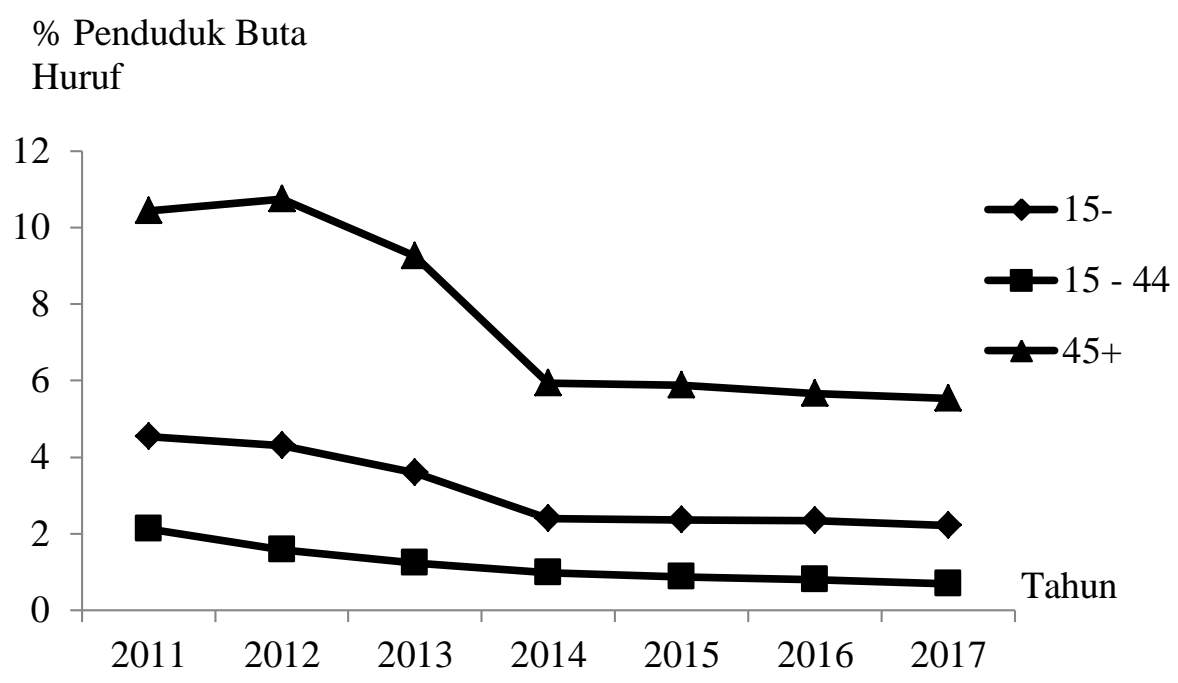

\section{Gambar 3. Grafik perbandingan persentase penduduk buta huruf pada usia dibawah 15 tahun, diantara 15 sampai 44 tahun,dandiatas 45 tahun}

Apabila persentase penduduk buta huruf dari jenjang usia dibawah 14 tahun sampai usia diatas 45 tahun dijumlahkan maka didapatlah persentase total penduduk buta huruf, sangat jelas terlihat tren grafik menurun seperti terlihat pada gambar 4. Yang berarti bahwa persentase total penduduk buta huruf dari tahun 2011 sampai 2017 di provinsi Kepulauan Bangka Belitung mengalami penurunan dari 17,41\% menjadi 2,91\%. Jadi pada tahun 2017 terdapat sekitar 2,91\% penduduk buta huruf atau sekitar 35. 597 jiwa dari jumlah penduduk Bangka Belitung sebanyak 1,223.329 jiwa. Jika dibandingkan angka penduduk buta huruf negara Indonesia 4,88\% atau sekitar 6.007.486., maka angka persentase buta huruf bangka Belitung lebih rendah 1,97\%. Jadi jelaslah terdapat 35.597 
Al-Ishlah: Jurnal Pendidikan - ISSN: 2087-949o (p); 2597-940X (e)

Vol. 11, No. 1 (2019)

Jumlah \% Penduduk

Buta Huruf

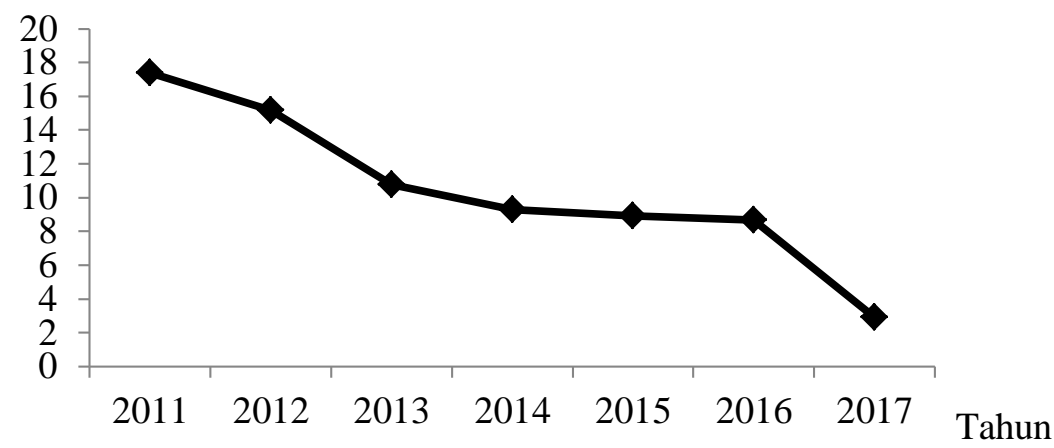

Gambar 4. Grafik perbandingan Persentase Penduduk buta huruf pada usia dibawah 15 tahun, diantara 15 sampai 44 tahun dan diatas 45 tahun

Dengan mengolah data jumlahrata-rata desa yang memiliki fasilitas sekolah sebagai variabel $\mathrm{X}$ dengan persentase jumlah total penduduk buta huruf di Provinsi Kepulauan Bangka Belitung sebagai variabel Y linear menggunakan metode regresi,didapatlah grafik regresi berikut seperti pada gambar 5 .

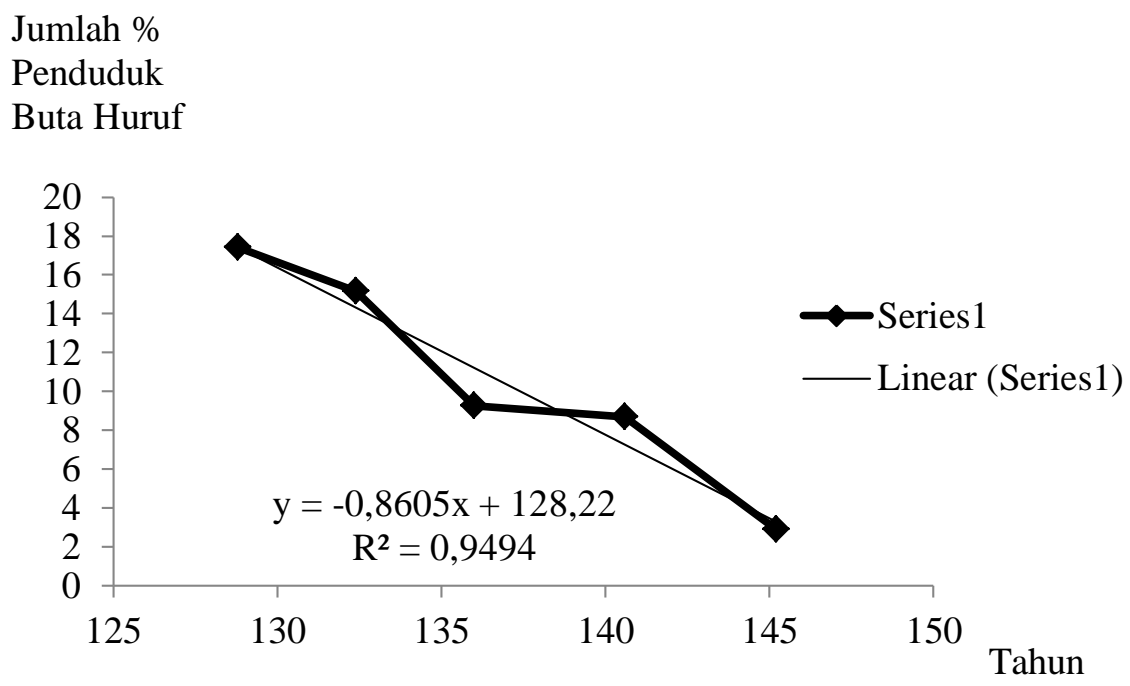

Gambar 5. Grafik regresi hubungan antara jumlahrata-rata desa yang memiliki fasilitas sekolah dengan perentase total penduduk buta huruf di Provinsi Kepulauan Bangka Belitung 
Al-Ishlah: Jurnal Pendidikan - ISSN: 2087-949o (p); 2597-940X (e)

Vol. 11, No. 1 (2019)

Dari grafik regresi di atas terlihat hubungan yang kuat antara jumlah total fasilitas sekolah dengan persentase total penduduk buta huruf yang dibuktikan dengan koefisien determinasi Pearson (R2 ) sebesar 0,940 (mendekati 1) dengan nilai p-value 0,0038 dan significance 0,0049 (mendekati nol). Ini menunjukan bahwa 95\% dari data penelitian menunjukan adanya hubungan antara jumlah desa-desa yang memiliki fasilitas sekolah dengan persentase penduduk buta huruf di Provinsi Kepulauan Bangka Belitung pada 2011 sampai 2018. Dari persamaan garis linear $\mathrm{Y}=-0,860 \mathrm{X}+128,2$ dan dari gambar grafik regresi yang menurun dapat dianalisis bahwa hubungan antara jumlah desa yang memiliki fasilitas sekolah dengan persentase penduduk buta huruf di Propinsi Kepulauan Bangka Belitung dari tahun 2011 sampai 2018 berbanding terbalik Dari tahun 2011 sampai 2018 terjadi peningkatan desa yang memiliki fasilitas sekolah, sebaliknya untuk pesrsentase jumlah penduduk buta huruf mengalami penurunan.

Dari tahun 2011 sampai 2018 telah terjadi peningkatan jumlah desa yang memiliki fasilitas sekolah. Hal ini menunjukan perkembangan yang baik dibidang pendidikan yang berimbas dengan menurunnya persentase penduduk buta huruf. Akan tetapi, sampai tahun 2018 masih tetap ada penduduk yang buta huruf, terutama pada penduduk usia lebih dari 45 tahun. Hal ini menunjukan masih adanya penduduk yang tidak dapat dijangkau oleh sekolah, terutama sekolah yang terletak jauh dipelosok atau di pulau-pulaukecil. Jadi, masih diperlukan upaya pemerintah untuk menjangkau penduduk ditempat-tempat terpencil agar desa-desa yang memiliki fasilitas sekolah tersebar merata ke seluruh pelosok desa di provinsi bisa terbebas dari buta huruf..

\section{SIMPULAN}

Berdasarkan penelitian yang telah dilakukan, dapat diambil kesimpulan bahwa telah terjadi peningkatan jumlah rata-rata desa yang memiliki fasilitas sekolah di Provinsi Kepulauan Bangka Belitung, yaitu dari 32\% menjadi $36 \%$. Sebaliknya, persentase penduduk buta huruf di Provinsi Kepulauan Bangka Belitung telah terjadi penurunan dari $17,41 \%$ menjadi $2,91 \%$. Angka 2,91\% ini lebih rendah jika dibandingkan persentase nasional sebesar 4,88\%. Berdasarkan analisis regresi dengan koefisien regresi sebesar 0,940 dan persamaan regresi $\mathrm{Y}=$ $-0,860 \mathrm{X}+128,2$ dapat diambil kesimpulan telah terjadi peningkatan jumlah desa yang memiliki fasilitas sekolah yang menyebabkan persentase penduduk buta huruf di Provinsi Kepulauan Bangka Belitung menurun. Analisis anova dengan nilai p-value 0,0038 dan significance 0,0049 menyatakan bahwa kesimpulan tersebut valid. 
Al-Ishlah: Jurnal Pendidikan - ISSN: 2087-949o (p); 2597-940X (e)

Vol. 11, No. 1 (2019)

\section{DAFTAR PUSTAKA}

Amah, Nik, \& Nugroho, Angga. (2015). Pengaruh Fasilitas Sekolah terhadap Hasil Belajar Akuntansi dengan Lingkungan Sosial sebagai Pemoderasi IKIP PGRI Madium.

Badan Pusat Statistik Provinsi Kepulauan Bangka Belitung. (2019).

Ditjen Kependudukan dan Catatan Sipil. Kemendagri. (2019).

Gesaf. (2008). Regresi dan Korelasi Sederhana, hhtp: //gesaf. files. wordpress. com/2008/11/regresi dan korelasi, pdf.

Maharani, Ratih, \& Setya, Winahju, Wiwiek. (2014). Pemodelan Angka Buta Huruf di Provinsi Sumatera Barat Tahun 2014 dengan Geogeaphically Weight Regeneration. Institut Teknologi Sepuluh November (ITS).

Megasari, Rika. (2019). Peningkatan Pengelolaan Sarana dan Prasarana Pendidikan untuk Meningkatkan Kualitas Pembelajaran Di SMP 5 Bukit Tinggi. UNP .

Mulyasa. (2011). Manajemen Berbasis Sekolah. Bandung.

Sopiatin, Popi. (2010). Manajemen Belajar Berbasis Kepuasan Siswa. Bogor.

Undang-undang Republik Indonesia No. 20 tahun 2003 tentang Sistem Pendidikan Nasional.

Vito, Benediktus, Krisnani, Hetty, \& Resnawati, Risna. (2019). Kesenjangan Pendidikan Desa dan kota.

Widiastuti, Novi. (2013). Penerapan Metode Pembelajaran Transliterasi Dalam Meningkatkan Hasil Belajar Keaksaraan. Universitas Pendidikan Indonesia. repository. upi. edu. 